\title{
Formation and mechanical properties of Zr-based bulk metallic glass composites with high oxygen levels
}

\author{
LIU ZengQian, YANG YaoWei, LI Ran, HUANG Lu \& ZHANG Tao* \\ Key Laboratory of Aerospace Materials and Performance (Ministry of Education), School of Materials Science and Engineering, \\ Beihang University, Beijing 100191, China
}

Received December 16, 2011; accepted March 12, 2012; published online July 16, 2012

\begin{abstract}
Zr-based bulk metallic glass (BMG) composites with in situ formed $\mathrm{Y}_{2} \mathrm{O}_{3}$ particle reinforcements were synthesized by proper additions of $\mathrm{Y}$ to ultrahigh-oxygen-containing glass-forming alloy precursors. Microstructures, thermal stabilities, and mechanical properties of the composites were investigated. Glass formation was greatly enhanced by Y additions in the alloys and the resultant particles were homogenously distributed in the glassy matrix, allowing for the fabrication of oxide dispersion strengthened BMG composites. The compressive strength and hardness increased by $10 \%$ and $20 \%$, respectively, with the introduction of $\mathrm{Y}_{2} \mathrm{O}_{3}$ particles. These results are significant for the design and production of Zr-based BMGs and BMG composites with improved properties using commercial high-oxygen content raw materials under industrial conditions.
\end{abstract}

bulk metallic glass, composites, oxide dispersion strengthened alloys, mechanical properties, in situ reaction

Citation: Liu Z Q, Yang Y W, Li R, et al. Formation and mechanical properties of Zr-based bulk metallic glass composites with high oxygen levels. Chin Sci Bull, 2012, 57: 3931-3936, doi: 10.1007/s11434-012-5293-x

Bulk metallic glasses (BMGs) have attracted much attention due to their scientific significance and potential engineering applications [1-3]. Compared with their crystalline counterparts, BMGs exhibit unique properties, such as large elastic strain limit of $\sim 2 \%$, high strength, and high corrosion resistance. For BMG matrix composites, chemical interactions between the glassy matrix and the introduced reinforcements usually occur slowly because of the relatively low melting temperatures of glass-forming alloys. This is expected to contribute to a good wettability between the two phases [4,5]. In addition, differential thermal stresses which may arise between the matrix and reinforcements during preparation can also be mitigated by the low glass transition temperature and small thermal expansion coefficient of BMGs [4,6,7]. Therefore, BMGs are of considerable importance as novel matrices used for the fabrication of metal matrix composites. Attempts have been made to introduce a reinforcing phase to the glassy matrix using ex situ or in situ methods. In situ methods are considered to be superior,

*Corresponding author (email: zhangtao@buaa.edu.cn) since the in situ reaction is effective for suppressing the agglomeration of dispersoids, achieving good wettability, and forming strong interfacial bonding between the matrix and reinforcements [4,5,8-10].

Oxide dispersion strengthened (ODS) crystalline alloys have been extensively studied due to their promising properties and applications in nuclear fission and fusion fields [11]. However, BMGs strengthened by oxide particles have rarely been reported [12,13], especially the in situ ODS BMG composites. Carbide particles were always adopted to reinforce the BMG matrix by adding graphite to the glassy precursor through their in situ reactions $[8,14,15]$. However, this method is not applicable in the fabrication of in situ ODS BMG composites, since it is difficult to introduce quantitative amounts of gaseous oxygen to the matrix during the preparation process. In addition, interfacial problems are of considerable significance in metal matrix composites. To maximize the interfacial bond strength, it is necessary to promote wetting and control the chemical reaction between the matrix and reinforcements, because intense reactions usually deteriorate the bond strength [4,5]. Therefore, a 
logical approach is to introduce the reinforcements through in situ reactions between elements in a solute state using the proper reaction diffusion process. Fortunately, oxygen has high solubility in the main constituents of some glassforming systems, such as $\mathrm{Zr}$ and $\mathrm{Ti}$ [16], which may contribute to high bond strength and homogenization of oxide reinforcements in the resultant ODS BMG composites.

Furthermore, glass-forming ability (GFA) and plasticity of Zr-based BMGs are usually deteriorated severely by oxygen impurity [17-22] (although some specific compositions were reported as exceptions very recently [23]). Considering that an increase in the oxygen content of an alloy is basically unavoidable during its preparation and service processes [23,24], the processing conditions are rather stringent for Zr-based BMGs and the recycling of their products difficult. It has been known that proper additions of rare earth metals can improve the GFA of Zr-based BMGs produced with low purity raw materials [25-27]. However, synergic effects of high oxygen levels (>1 at.\%) and corresponding rare earth metal additions on the glass formation and mechanical properties of $\mathrm{Zr}$-based BMGs have not been systematically investigated. It is supposed that a good understanding of this issue will provide important guidance and implications for lowering the manufacturing cost, widening the applications, and facilitating the recycling of BMGs.

In this work, high strength Zr-based ODS BMG composites with uniformly distributed $\mathrm{Y}_{2} \mathrm{O}_{3}$ particle reinforcements were successfully synthesized by an in situ method. Variations in GFA of the composite matrices were evaluated. Microstructures, thermal stabilities, and mechanical properties of the composites were investigated.

\section{Experimental}

Homogenous $\mathrm{Zr}(\mathrm{O})$ solid solutions with different nominal oxygen contents were obtained by arc melting mixtures of $\mathrm{ZrO}_{2}$ solid lumps (99 wt.\% purity) and crystal bar $\mathrm{Zr}(99.5$ wt.\% purity, with an oxygen content of less than $150 \mathrm{ppm}$ ) on a water-cooled copper hearth under Ti-gettered high-purity argon atmosphere. Subsequently, master ingots with designed compositions of $\left(\mathrm{Zr}_{0.55} \mathrm{Al}_{0.10} \mathrm{Ni}_{0.05} \mathrm{Cu}_{0.30}\right)_{100-5 x}\left(\mathrm{Y}_{0.4} \mathrm{O}_{0.6}\right)_{5 x}(x=$ $0,0.5$ at.\%, 1 at.\%, and 2 at.\%) were prepared by arc melting the pre-alloyed $\mathrm{Zr}(\mathrm{O})$ with pure $\mathrm{Al}, \mathrm{Ni}, \mathrm{Cu}$, and $\mathrm{Y}$ (all above 99.9 wt.\% purity). The weight loss of each ingot after the two-step melting process was less than $0.2 \%$. The master alloys were then remelted in a quartz tube by induction and injected into copper moulds with cylindrical cavities in diameters ranging from 2 to $8 \mathrm{~mm}$. Structures of the as-cast rods were analyzed using a Bruker AXS D8 X-ray diffractometer (XRD) with $\mathrm{Cu} \mathrm{K \alpha}$ radiation. Microstructures of the transversal and longitudinal sections of the specimens were investigated by an OLYMPUS BX51M optical microscope (OM) and a Hitech-3500N scanning electron microscope
(SEM) equipped with an energy-dispersive X-ray spectroscope (EDX) at $20 \mathrm{kV}$ acceleration voltage. Thermal stabilities were studied by a NETZSCH DSC $404 \mathrm{C}$ differential scanning calorimeter (DSC) at a heating rate of $0.33 \mathrm{~K} \mathrm{~s}^{-1}$ in flowing argon gas. Compression tests were performed on samples with a diameter of $2 \mathrm{~mm}$ and an aspect ratio of $\sim 2: 1$ at room temperature under a strain rate of $2 \times 10^{-4} \mathrm{~s}^{-1}$. Morphology of the fractured samples was analyzed by SEM. Vickers hardness $\left(H_{\mathrm{v}}\right)$ was measured at a testing load of $5 \mathrm{~N}$ and a dwell time of $10 \mathrm{~s}$.

\section{Results and discussion}

Figure 1 shows the XRD patterns of the as-cast $2 \mathrm{~mm}$ diameter $\left(\mathrm{Zr}_{0.55} \mathrm{Al}_{0.10} \mathrm{Ni}_{0.05} \mathrm{Cu}_{0.30}\right)_{100-5 x}\left(\mathrm{Y}_{0.4} \mathrm{O}_{0.6}\right)_{5 x}$ rods taken from the longitudinal sections as well as the $\mathrm{ZrO}_{2}$ powders. Compared with the pattern of monolithic metallic glass showing only a broad diffraction maximum, patterns for the samples with $x>0$ exhibit superimposition of a broad halo peak characteristic of the glassy phase and sharp peaks from crystalline phases. The peak positions match exactly with those of $\mathrm{Y}_{2} \mathrm{O}_{3}$ and the peak intensity increases with the increase in $x$ from 0.5 to 2 . No other crystalline phases, not even the initial $\mathrm{ZrO}_{2}$, were detected within the sensitivity limit of XRD. This indicates that $\mathrm{ZrO}_{2}$ has reacted with $\mathrm{Y}$ and produced the crystalline $\mathrm{Y}_{2} \mathrm{O}_{3}$ following the simplified chemical reaction:

$$
\begin{gathered}
3 \mathrm{ZrO}_{2}+4 \mathrm{Y} \rightarrow 3 \mathrm{Zr}+2 \mathrm{Y}_{2} \mathrm{O}_{3}, \\
\Delta G^{0}=-517735+13.71 T .
\end{gathered}
$$

The change in standard Gibbs free energy $\left(\Delta G^{0}\right)$ for this reaction was theoretically calculated according to the thermodynamic data [28]. $\Delta G^{0}$ remains negative in the practical temperature range, allowing for the successful introduction of $\mathrm{Y}_{2} \mathrm{O}_{3}$ through the above reaction. Furthermore,

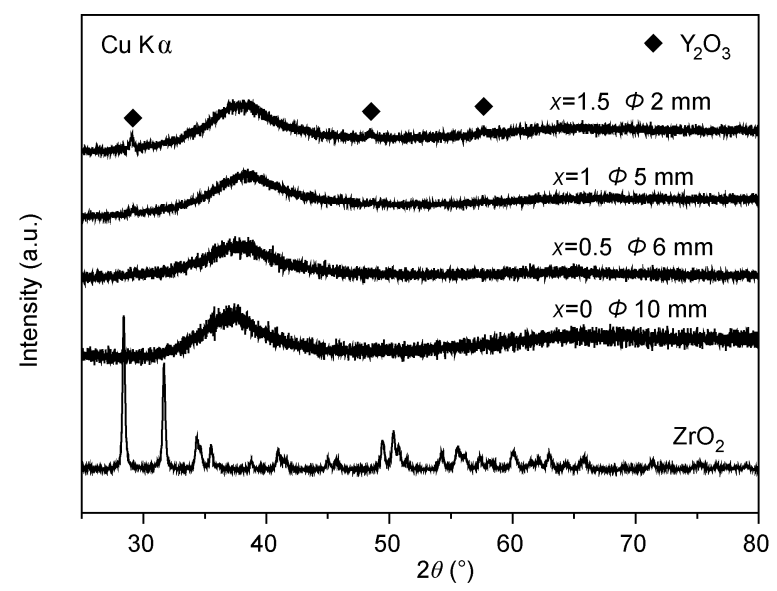

Figure 1 XRD patterns of as-cast rods with different diameters for the $\left(\mathrm{Zr}_{0.55} \mathrm{Al}_{0.10} \mathrm{Ni}_{0.05} \mathrm{Cu}_{0.30}\right)_{100-5 x}\left(\mathrm{Y}_{0.4} \mathrm{O}_{0.6}\right)_{5 x}$ alloys $(x=0,0.5,1,2)$. XRD pattern of $\mathrm{ZrO}_{2}$ powders is also shown for comparison. 
the small amount of $\mathrm{Zr}$ yielded by this reaction dissolved into the matrix to form an amorphous phase. This prevented an obvious deviation of the matrix composition, thus maintained its good GFA. In reality, the matrix alloy containing 1.5 at.\% oxygen cannot be cast into a bulk glassy form (diameter $\geqslant 1 \mathrm{~mm}$ ) without the corresponding $\mathrm{Y}$ addition (the XRD pattern not shown here). The critical diameters of the rods that maintained the amorphous nature of the matrix were further determined to be 6 and $5 \mathrm{~mm}$ for the composites when $x=0.5$ and 1 , respectively. Therefore, proper additions of $\mathrm{Y}$ in the high-oxygen-containing Zr-based alloys improved the GFA of the matrix significantly and allowed for the fabrication of ODS BMG composites.

Further evidence was provided by the OM images of the specimens. As shown in Figure 2(a), particles in size of $\sim 5-20 \mu \mathrm{m}$ arranged in an irregular morphology were embedded in the amorphous matrix. Volume fractions of reinforcements in the samples with $x=0.5,1$ and 2 were measured by SISC IAS 8.0 optical image analyzer software to be $1.8 \mathrm{vol} \%$, $3.7 \mathrm{vol} \%$, and $5.2 \mathrm{vol} . \%$, respectively. Images of the transversal and longitudinal sections show that the particles were homogenously distributed throughout the entire rods. Agglomeration which may be encountered in composites synthesized by ex situ methods [5] was not observed in these samples (Figure 2(b) and (c)). In addition, the sizes of the particles were uniform from the center to the edge, regardless of the difference in cooling rate during casting. Neither pores nor voids were detected at the interfaces between particles and matrix, indicating a true bonding state between the two phases, as shown in the magnified SEM micrograph in Figure 2(d). To investigate the chemical compositions, EDX analysis was performed on both phases (insets of Figure 2(d)). The results showed that particles mainly consisted of $\mathrm{Y}$ and $\mathrm{O}$. This further confirmed that crystalline particles were $\mathrm{Y}_{2} \mathrm{O}_{3}$ oxides combining with XRD patterns. The matrix contained only $\mathrm{Zr}, \mathrm{Al}, \mathrm{Ni}$, and $\mathrm{Cu}$ within the EDX sensitivity, indicating no obvious change in matrix composition after the in situ reaction. Furthermore, no other crystalline phases besides $\mathrm{Y}_{2} \mathrm{O}_{3}$ were detected within the sensitivity of OM and SEM, which further validates the ODS composite structure of the obtained samples.

Thermal stabilities of the composites were investigated by DSC with curves shown in Figure 3. The alloys exhibited an apparent endothermic heat event characteristic of glass transition followed by an exothermic heat release event, which confirming the amorphous nature of the matrix. Values of the glass transition temperature $T_{\mathrm{g}}$, onset crystallization temperature $T_{\mathrm{x}}$, and supercooled liquid region before crystallization $\Delta T_{\mathrm{x}}\left(=T_{\mathrm{x}}-T_{\mathrm{g}}\right)$ were derived from DSC curves and presented in Table 1. $\Delta T_{\mathrm{x}}$, which always represents
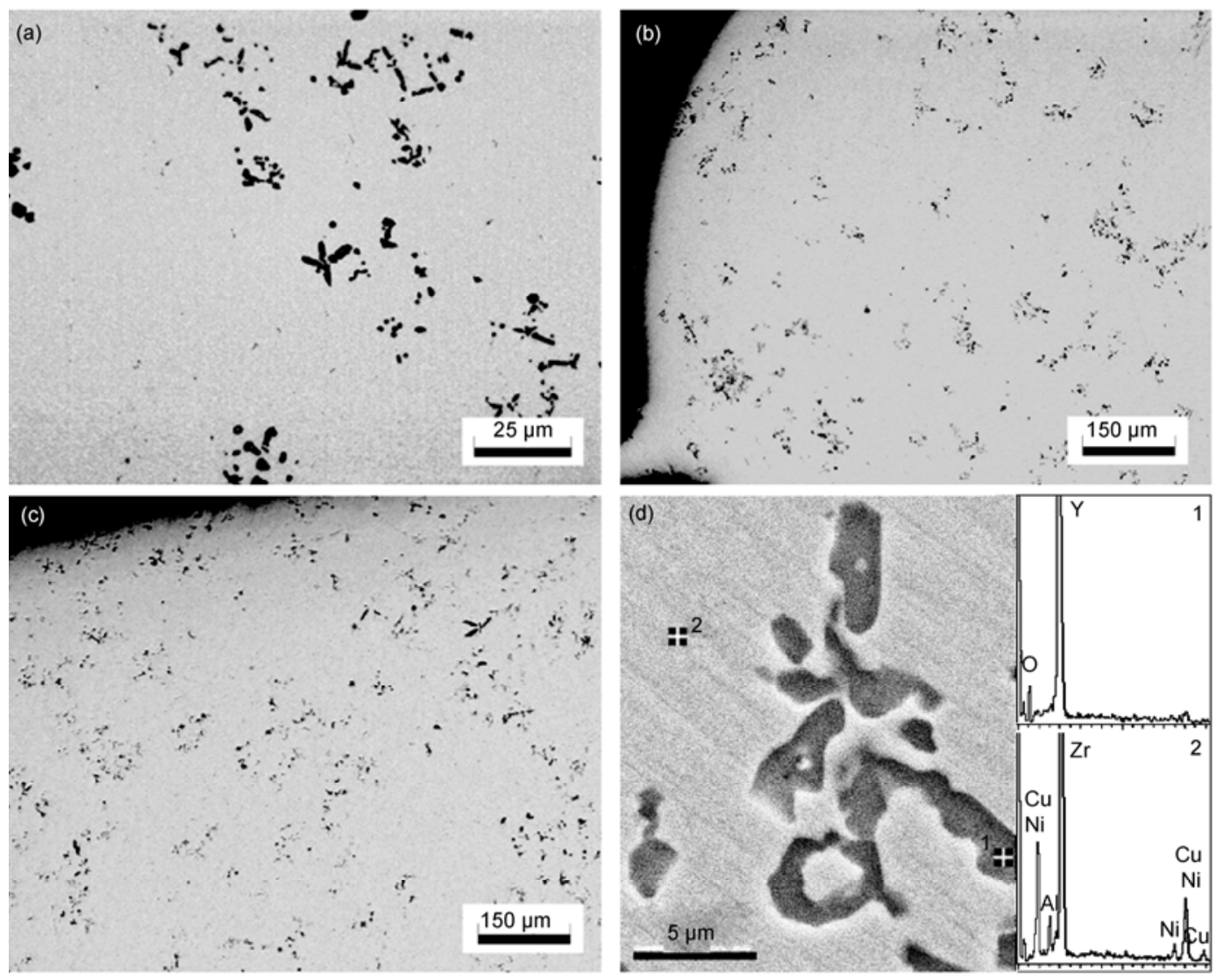

Figure 2 (a) $\mathrm{OM}$ images of the composite containing 3.7 vol. $\% \mathrm{Y}_{2} \mathrm{O}_{3}$ particles. SEM images of (b) transversal (1.8 vol.\% $\left.\mathrm{Y}_{2} \mathrm{O}_{3}\right)$ and (c) longitudinal sections (5.2 vol. $\% \mathrm{Y}_{2} \mathrm{O}_{3}$ ) of the as-cast rods. (d) Magnified view of the 1.8 vol.\% $\mathrm{Y}_{2} \mathrm{O}_{3}$ composite by SEM with the EDX results for the particle and matrix. 


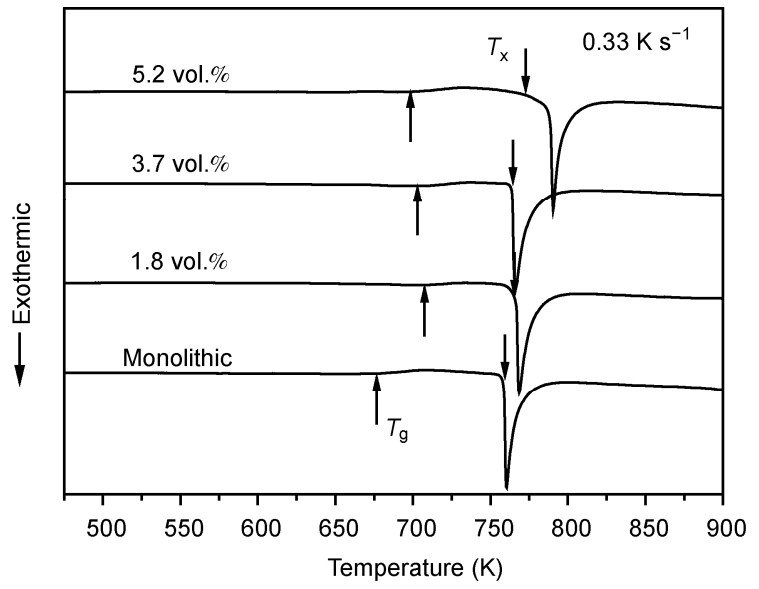

Figure 3 DSC curves of the $2 \mathrm{~mm}$ as-cast rods for the monolithic BMG and $\mathrm{BMG}$ composites with different volume fractions of $\mathrm{Y}_{2} \mathrm{O}_{3}$ particles.

the thermal stability of amorphous alloys, was lower than that of the monolithic metallic glass for the composites. In fact, slight dissolution of oxygen can strongly affect the thermal parameters of $\mathrm{Zr}$-based BMGs and decrease their thermal stabilities $[17,18]$.

The $\mathrm{Zr}_{55} \mathrm{Al}_{10} \mathrm{Ni}_{5} \mathrm{Cu}_{30}$ matrix has a liquidus temperature of $\sim 1148 \mathrm{~K}$ as obtained by DSC. Considering that certain overheating temperature was required for the casting of glass-forming alloys [24], casting temperature of the composites was estimated to be $\sim 1400 \mathrm{~K}$ in this study, much lower than the melting point of $\mathrm{Y}_{2} \mathrm{O}_{3}(\sim 2703 \mathrm{~K})$ [16]. Thus before casting, $\mathrm{Y}_{2} \mathrm{O}_{3}$ particles have already existed in the melt which allowed a sufficient mixing of the particles and glass-forming liquid through radio frequency stirring. Therefore, sizes of the particles were independent from the cooling rate during casting and a highly uniform distribution without agglomeration was attained in the composites. In addition, differential thermal stresses between the two phases was also expected to be decreased by the low $T_{\mathrm{g}}$ $(\sim 676 \mathrm{~K})$ and small thermal expansion coefficient $\left(\sim 1 \times 10^{-5}\right.$ $\mathrm{K}^{-1}$, measured by thermal expansion experiments) of the matrix. Furthermore, temperate in situ reaction contributed to a proper wettability and good homogenization of the reinforcements as well [4].

It has been reported that oxygen in glass-forming systems can promote the formation of ultrafine heterogeneous nucleation sites consisting of oxides or oxygen-containing metastable crystals. This accelerates further crystallization of the alloys and thus deteriorates the GFA $[18,19,25]$. Because of the strong affinity between $\mathrm{Y}$ and $\mathrm{O}$, oxygen can be fixed in the resultant $\mathrm{Y}_{2} \mathrm{O}_{3}$ particles by $\mathrm{Y}$ additions in the present high-oxygen-containing alloys. Thus the deleterious effect of oxygen can be mitigated and the glassy matrix is further reinforced by the particles. However, the second phase also acts as heterogeneous sites for the nucleation of crystals [29]. As a result, GFA of the matrix decreases with an increase in the volume fraction of reinforcements. The wettability between the reinforcements and the matrix is crucial for the heterogeneous nucleation. A small wetting angle $\theta$ produces low nucleation energy following the relation given by [29]

$$
\Delta G_{\mathrm{he}}=\frac{2-3 \cos \theta+\cos ^{3} \theta}{4} \Delta G_{\mathrm{ho}},
$$

where $\Delta G_{\text {he }}$ and $\Delta G_{\text {ho }}$ are the energy needed for heterogeneous and homogeneous nucleation, respectively. In the range from $\theta=0$ to $\theta=\pi, \Delta G_{\mathrm{he}}$ decreases monotonically with the reducing $\theta$. Consequently, good wettability (i.e. smaller $\theta$ ) favors the crystallization and deteriorates GFA of the matrix, although it contributes to a strong interfacial bond strength. Therefore, the GFA of matrix and the interfacial bond strength should be balanced intentionally in the designing of BMG composites. Chemical wetting can be attained by the in situ reaction, but an intense reaction usually yields immoderate wetting which is deleterious to GFA. Thus an appropriate chemical wetting attained by temperate reaction through the proper diffusion process of the solute elements is advantageous for achieving strong interfacial bonding, as well as maintaining an acceptable GFA of the matrix. In this study, the bond strength and glass formation were well balanced for the ODS composites, because the $\mathrm{Y}_{2} \mathrm{O}_{3}$ particles were introduced by the in situ reaction between the added $\mathrm{Y}$ and the solute oxygen using its diffusion process. Furthermore, certain duration time is needed for the reaction to eliminate the dissolved oxygen impurity better, which requires a good stability of the reinforcements to prevent the invalidation and poisoning of the particles [30]. $\mathrm{Y}_{2} \mathrm{O}_{3}$ has excellent thermal and chemical stabilities even at high temperatures, thus allowing for the fine decontamination of matrix and the stable strengthening effect of the reinforcements.

Compression tests and Vickers hardness measurements were conducted to evaluate the mechanical properties of the composites. Figure 4(a) shows the compressive stress-strain curves of the as-cast Zr-based monolithic BMG and ODS BMG composites containing different volume fractions of $\mathrm{Y}_{2} \mathrm{O}_{3}$ particles. The dependences of compressive strength and Vickers hardness on the $\mathrm{Y}_{2} \mathrm{O}_{3}$ volume fractions are presented in Figure 4(b). The compressive strength $\sigma$ increases from $\sim 1770 \mathrm{MPa}$ for the BMG to $1960 \mathrm{MPa}$ for the composite with 3.7 vol. $\% \mathrm{Y}_{2} \mathrm{O}_{3}$ reinforcements. It is proposed that crystalline particles embedded in the glassy matrix can restrict the slipping of shear bands, thus leading to an increase in the compressive strength [5,8]. In addition, a slight serrated flow is visible for composites containing $1.8 \mathrm{vol} \%$ and 3.7 vol. $\% \mathrm{Y}_{2} \mathrm{O}_{3}$ particles although the composites failed in a brittle manner. Vein patterns, closely related to localized adiabatic heating during inhomogeneous flow in metallic glasses [31], were observed on the fracture surface of the composites, as shown in Figure 5. The blocking effect of the particles on the propagation of shear bands can be manifested by the embedded particles on the fracture surface. For the composite with 5.2 vol. $\% \mathrm{Y}_{2} \mathrm{O}_{3}$ particles, however, the 

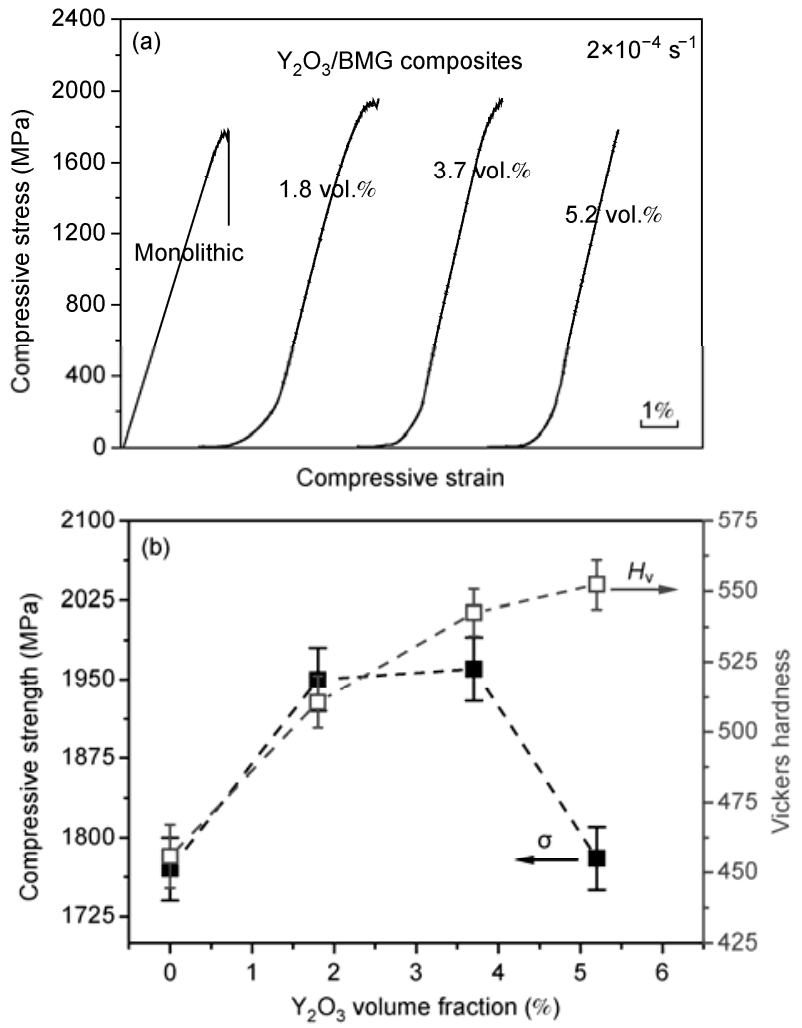

Figure 4 (a) Compressive stress-strain curves of the as-cast $\mathrm{Zr}$-based monolithic BMG and BMG composites; (b) $\mathrm{Y}_{2} \mathrm{O}_{3}$ volume fraction dependence of the yield strength and Vickers hardness.

measured strength is unreasonably low compared with those of composites with lower $\mathrm{Y}_{2} \mathrm{O}_{3}$ volume fractions. One possible reason may be that the yield strength is difficult to access experimentally because of the brittleness of the composites. On the other hand, the $H_{\mathrm{v}}$ increases monotonously with the increase in the volume fraction of reinforcements in the composites. Hardness of the composite containing 5.2 vol. $\% \mathrm{Y}_{2} \mathrm{O}_{3}$ was enhanced by $20 \%$ from $H_{\mathrm{v}}$ 460 of the monolithic BMG to $H_{\mathrm{v}} 552$. The $H_{\mathrm{v}}$ values of the alloys are also listed in Table 1. It is speculated that the hardness of the composites mainly depends on the hardness and volume fractions of individual components [4]. The hardness of $\mathrm{Y}_{2} \mathrm{O}_{3}$ is higher than that of monolithic BMG [32], and hence, the hardness of composite was improved monotonously with increased $\mathrm{Y}_{2} \mathrm{O}_{3}$ volume fractions. Therefore, this in situ method is effective and simple in the

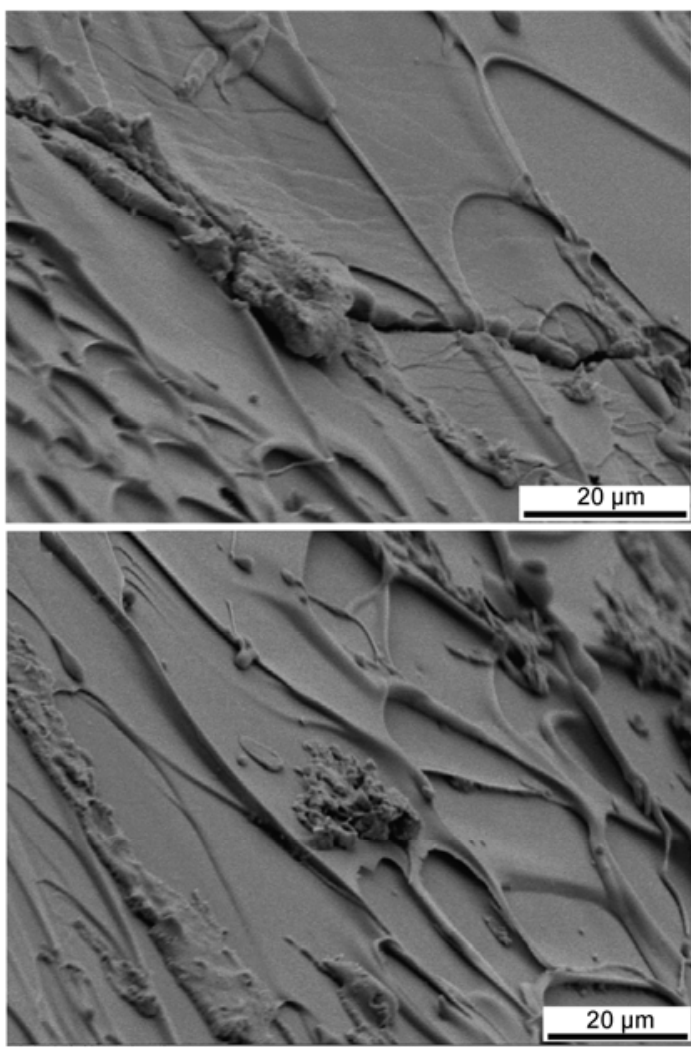

Figure 5 SEM images of the fracture surface for the composites with 1.8 vol. $\% \mathrm{Y}_{2} \mathrm{O}_{3}$ particles.

synthesis of high-strength ODS BMG composites. The results are significant for the fabrication of Zr-based BMGs/ BMG composites with improved mechanical properties under industrial conditions with high oxygen levels.

\section{Conclusions}

Oxide dispersion strengthened bulk metallic glass composites with in situ $\mathrm{Y}_{2} \mathrm{O}_{3}$ reinforcements were successfully synthesized by injection casting method. The glass-forming ability of high-oxygen-containing Zr-based alloys was greatly enhanced by proper additions of $\mathrm{Y}$ and the resultant uniformly distributed $\mathrm{Y}_{2} \mathrm{O}_{3}$ particles exhibited good interfacial bonding with the glassy matrix. The compressive strength and hardness of the composites were significantly

Table 1 Thermal parameters, mechanical properties at room temperature, and the critical diameters for the glass formation $\left(d_{\mathrm{c}}\right)$ of $\left(\mathrm{Zr}_{0.55} \mathrm{Al}_{0.10} \mathrm{Ni}_{0.05^{-}}\right.$ $\left.\mathrm{Cu}_{0.30}\right)_{100-5 x}\left(\mathrm{Y}_{0.4} \mathrm{O}_{0.6}\right)_{5 x}(x=0,0.5,1,2) \mathrm{BMG}$ and $\mathrm{BMG}$ composites containing various volume fractions of $\mathrm{Y}_{2} \mathrm{O}_{3}$ particles

\begin{tabular}{|c|c|c|c|c|c|c|c|}
\hline $\begin{array}{c}\text { Nominal composition } \\
\left(\mathrm{Zr}_{0.55} \mathrm{Al}_{0.10} \mathrm{Ni}_{0.05} \mathrm{Cu}_{0.30}\right)_{100-5 x}\left(\mathrm{Y}_{0.4} \mathrm{O}_{0.6}\right)_{5 x}\end{array}$ & $\begin{array}{l}\text { Volume fraction } \\
\text { (vol.\%) }\end{array}$ & $T_{\mathrm{g}}(\mathrm{K})$ & $T_{\mathrm{x}}(\mathrm{K})$ & $\Delta T_{\mathrm{x}}(\mathrm{K})$ & $\sigma_{\max }(\mathrm{MPa})$ & $H_{\mathrm{v}}$ & $d_{\mathrm{c}}(\mathrm{mm})$ \\
\hline$x=0$ & 0 & 676 & 759 & 83 & 1770 & $459.5 \pm 11$ & $>10$ \\
\hline$x=0.5$ & 1.8 & 708 & 766 & 58 & 1950 & $510.7 \pm 9$ & 6 \\
\hline$x=1$ & 3.7 & 703 & 764 & 61 & 1960 & $542.5 \pm 8$ & 5 \\
\hline$x=2$ & 5.2 & 698 & 772 & 74 & 1780 & $552.4 \pm 9$ & 2 \\
\hline
\end{tabular}


improved by the introduction of $\mathrm{Y}_{2} \mathrm{O}_{3}$ reinforcements. This study has important implications in lowering the manufacturing cost and recycling of Zr-based BMGs and is significant in the fabrication of BMG composites with improved mechanical properties under industrial conditions.

This work was supported by the National Basic Research Program of China (2007CB613900), the National Natural Science Foundation of China (51071008), and the Innovation Foundation of BUAA for PhD Graduates and Fundamental Research Funds for the Central Universities.

1 Johnson W L. Bulk glass-forming metallic alloys: Science and technology. MRS Bull, 1999, 24: 42-56

2 Inoue A. Stabilization of metallic supercooled liquid and bulk amorphous alloys. Acta Mater, 2000, 48: 279-306

3 Zhang T, Yang Q, Ji Y F, et al. Centimeter-scale-diameter Co-based bulk metallic glasses with fracture strength exceeding $5000 \mathrm{MPa}$. Chin Sci Bull, 2011, 56: 3972-3977

4 Clyne T W, Withers P J. An Introduction to Metal Matrix Composites. Cambridge: Cambridge University Press, 1993

5 Liu T, Shen P, Qiu F, et al. Synthesis and mechanical properties of TiC-reinforced $\mathrm{Cu}$-based bulk metallic glass composites. Scripta Mater, 2009, 60: 84-87

6 Choi-Yim H, Johnson W L. Bulk metallic glass matrix composites. Appl Phys Lett, 1997, 71: 3808-3810

7 Liu Z Q, Li R, Huang L, et al. Coring micron- and milli-scale holes in metallic glasses. J Non-Cryst Solids, 2011, 357: 3190-3194

8 Fu H M, Zhang H F, Wang H, et al. Synthesis and mechanical properties of $\mathrm{Cu}$-based bulk metallic glass composites containing in situ TiC particles. Scripta Mater, 2005, 52: 669-673

9 Wu Y, Song W L, Zhang Z Y, et al. Relationship between composite structures and compressive properties in CuZr-based bulk metallic glass system. Chin Sci Bull, 2011, 56: 3960-3964

10 Liu Z Q, Li R, Liu G, et al. Microstructural tailoring and improvement of mechanical properties in $\mathrm{CuZr}$-based bulk metallic glass composites. Acta Mater, 2012, 60: 3128-3139

11 Klueh R L, Shingledecker J P, Swindeman R W, et al. Oxide dispersion-strengthened steels: A comparison of some commercial and experimental alloys. J Nucl Mater, 2005, 341: 103-114

12 Kimura H, Takada F. Mechanically alloyed amorphous metallic powders with second phase particles. Mater Sci Eng, 1988, 97: 53-57

13 Eckert J, Seidel M, Kübler A, et al. Oxide dispersion strengthened mechanically alloyed amorphous $\mathrm{Zr}-\mathrm{Al}-\mathrm{Cu}-\mathrm{Ni}$ composites. Scripta Mater, 1998, 38: 595-602

14 Kato H, Hirano T, Matsuo A, et al. High strength and good ductility of $\mathrm{Zr}_{55} \mathrm{Al}_{10} \mathrm{Ni}_{5} \mathrm{Cu}_{30}$ bulk glass containing $\mathrm{ZrC}$ particles. Scripta Mater,
2000, 43: 503-507

15 Wang W H, Bai H Y. Carbon-addition-induced bulk ZrTiCuNiBe amorphous matrix composite containing $\mathrm{ZrC}$ particles. Mater Lett, 2000, 44: 59-63

16 Massalski T B, Okamoto H, Subramaniam P R, et al. Binary Alloy Phase Diagrams. Materials Park, OH: ASM Int, 1990

17 Lin X H, Johnson W L, Rhim W K. Effects of oxygen impurity on crystallization of an undercooled bulk glass-forming $\mathrm{Zr}-\mathrm{Ti}-\mathrm{Cu}-\mathrm{Ni}-\mathrm{Al}$ alloy. Mater Trans JIM, 1997, 38: 473-477

18 Gebert A, Eckert J, Schultz L. Effect of oxygen on phase formation and thermal stability of slowly cooled $\mathrm{Zr}_{65} \mathrm{Al}_{7.5} \mathrm{Cu}_{17.5} \mathrm{Ni}_{10}$ metallic glass. Acta Mater, 1998, 46: 5475-5482

19 Liu C T, Chisholm M F, Miller M K. Oxygen impurity and microalloying effect in a $\mathrm{Zr}$-based bulk metallic glass alloy. Intermetallics, 2002, 10: 1105-1112

20 Conner R D, Maire R E, Johnson W L. Effect of oxygen concentration upon the ductility of amorphous $\mathrm{Zr}_{57} \mathrm{Nb}_{5} \mathrm{Al}_{10} \mathrm{Cu}_{15.4} \mathrm{Ni}_{12.6}$. Mater Sci Eng A, 2006, 419: 148-152

$21 \mathrm{Lu} \mathrm{Z} \mathrm{P,} \mathrm{Bei} \mathrm{H,} \mathrm{Wu} \mathrm{Y,} \mathrm{et} \mathrm{al.} \mathrm{Oxygen} \mathrm{effects} \mathrm{on} \mathrm{plastic} \mathrm{deformation} \mathrm{of}$ a Zr-based bulk metallic glass. Appl Phys Lett, 2008, 92: 011915

22 Liu Z Q, Li R, Wang H, et al. Nitrogen-doping effect on glass formation and primary phase selection in Cu-Zr-Al alloys. J Alloys Compd, 2011, 509: 5033-5037

23 Wang Y X, Yang H, Lim G, et al. Glass formation enhanced by oxygen in binary Zr-Cu system. Scripta Mater, 2010, 62: 682-685

24 Mao J, Zhang H F, Fu H M, et al. The effects of casting temperature on the glass formation of Zr-based metallic glasses. Adv Eng Mater, 2009, 11: 986-991

25 Wang W H, Bian Z, Wen P, et al. Role of addition in formation and properties of Zr-based bulk metallic glasses. Intermetallics, 2002, 10: 1249-1257

26 Jiang F, Wang Z J, Zhang Z B, et al. Formation of Zr-based bulk metallic glasses from low purity materials by scandium addition. Scripta Mater, 2005, 53: 487-491

27 Yan M, Shen J, Zhang T, et al. Enhanced glass-forming ability of a Zr-based bulk metallic glass with yttrium doping. J Non-Cryst Solids, 2006, 352: 3109-3112

28 Dean J A. Lange's Handbook of Chemistry. New York: McGrawHill, 1999

29 Kashchiev D. Nucleation: Basic Theory with Applications. Oxford: Butterworth-Heinemann, 2003

30 Choi-Yim H, Schroers J, Johnson W L. Microstructures and mechanical properties of tungsten wire/particle reinforced $\mathrm{Zr}_{57} \mathrm{Nb}_{5} \mathrm{Al}_{10} \mathrm{Cu}_{15.4}$ $\mathrm{Ni}_{12.6}$ metallic glass matrix composites. Appl Phys Lett, 2002, 80: 1906-1908

31 Liu Z Q, Li R, Wang G, et al. Quasi phase transition model of shear bands in metallic glasses. Acta Mater, 2011, 59: 7416-7424

32 Lide D R. CRC Handbook of Chemistry and Physics. Boca Raton: CRC Press, 1998

Open Access This article is distributed under the terms of the Creative Commons Attribution License which permits any use, distribution, and reproduction in any medium, provided the original author(s) and source are credited. 